\title{
Journal club: Integrating research awareness into postgraduate nurse training
}

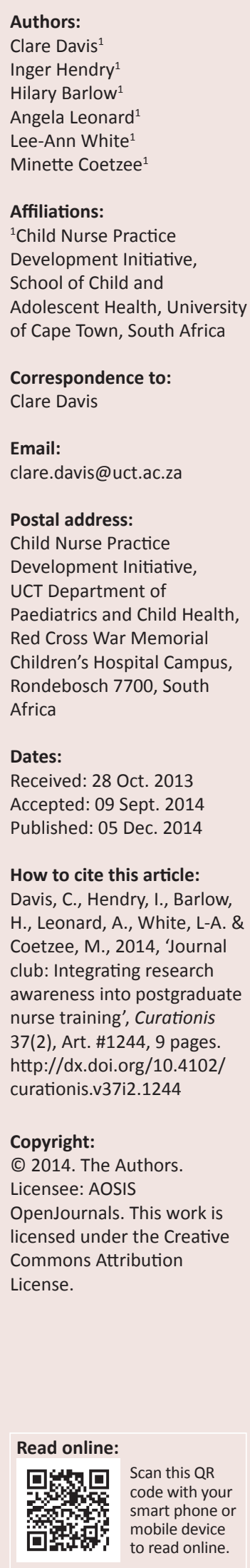

Background: Evidence-based nursing requires nurses to maintain an awareness of recently published research findings to integrate into their clinical practice. In the South African setting keeping up with recent literature has additional challenges, including the diversity of nurses' home language, geographically foreign origins of published work, and limited economic resources. Students enrolled in a postgraduate programme came from various paediatric settings and displayed limited awareness of nursing literature as an evidence base for practice.

Objectives: The study aimed to design and introduce a journal club as an educational strategy into the postgraduate programmes in children's nursing at the University of Cape Town (UCT), and then to refine the way it is used to best serve programme outcomes and facilitate student learning whilst still being an enjoyable activity.

Method: An action research methodology using successive cycles of 'assess-plan-act-observe' was used to design, implement and refine the structure of a journal club within the postgraduate diploma programme over four academic years. Six educators actively tracked and reflected on journal club sessions, and then analysed findings during and after each annual cycle to plan improvement and increasing programme alignment.

Results: Considerable refinement of the intervention included changing how it was structured, the preparation required by both students and educators, the article selection process and the intervention's alignment with other learning activities in the programme.

Conclusion: Journal club facilitated an increase in student awareness and reading of nursing literature, offering the opportunity to consider application of published research to current nursing practice. Another benefit was enabling students to become familiar with the specialised and technical language of research, children's nursing and the critical care of children and neonates, by speaking about these in peer settings.

\section{Introduction \\ Problem statement}

Children's nurses, like their colleagues in other health disciplines, are expected to maintain an awareness of the published evidence base of children's nursing and apply it to practice in their clinical settings. Applying published evidence in local settings is not a simple undertaking. Accessing and reading the literature and understanding what has been published are the first hurdles. Applying developed evidence in clinical settings poses the next hurdle. In South Africa, and other settings with fewer or different human and technical resources, not all published outcomes are applicable. This means that the reader requires skills of critical appraisal to determine the value of the science and critical reflection to consider whether published findings apply to local practice settings.

In the context of a set of postgraduate programmes that educate children's nurses, students displayed a limited awareness of primary nursing literature, or the fact that published literature could inform clinical practice in their settings, despite all being registered nurses from various paediatric settings in South Africa and other African countries.

Numerous strategies have been described and implemented to address the challenge of increasing awareness and reading of recent publications amongst health professionals. One strategy is the implementation of a journal club, which is not well described in educational settings in lower-resourced countries.

\section{Aim of the study}

This study aimed to introduce journal clubs as an educational strategy to assist registered nurses entering a postgraduate programme with the challenges related to awareness, accessing and reading of current literature and appraising the application of research to local practice. Students 
in the postgraduate programmes in children's nursing at the University of Cape Town (UCT) are expected to access and use relevant literature in assignments and to apply the emerging evidence base to practice in their local clinical settings. Researchers were committed to find out how a journal club could best assist students in meeting these broader programme expectations and facilitate student learning, whilst also being an enjoyable activity.

\section{Background and study context}

In the last 10 years South Africa has seen the introduction of the National Qualifications Framework Act (South African Qualifications Authority (SAQA) 2009) and a shift to more academically prepared professionals. The Framework is 'a principal instrument through which national education and training qualifications are recognised and quality-assured' (SAQA 2009:1).

In nursing this has resulted in registered nurses increasingly being prepared through four-year degree programmes which, by definition, include research literacy, awareness and possibly some application of literature to practice. The majority of currently practising registered nurses, however, were trained in diploma programmes with a limited research requirement or focus. As directed by the Qualifications Sub-Framework (SAQA 2013), specialist nurse training, previously offered in South Africa as advanced or post-basic diploma programmes, are now gradually being replaced by postgraduate diploma programmes like those offered by the UCT Division of Nursing and Midwifery.

The Child Nurse Practice Development Initiative is a nurseled unit in the UCT Department of Paediatrics and Child Health and based at Red Cross War Memorial Children's Hospital, Cape Town, South Africa. It works in collaboration with the Division of Nursing and Midwifery and offers the discipline-specific and clinical practice components of both of the postgraduate diploma programmes in children's nursing (child and critical care child nursing). The Initiative supports training and practice of children' nurses and encourages nurses to align their practice with current evidence. Two main areas of focus include working with small nursing teams to achieve best outcomes for children by finding local solutions to improve practice, and the formal education of specialist children's nurses.

Working in both clinical practice and educational settings revealed that registered nurses had little access to and experience of reading academic articles, and as a result had little knowledge of applying current nursing and research evidence and thinking to their practice. Whilst many of the barriers were comparable to those described in the international literature, three additional challenges were observed: academic language, the fact that published work is often from foreign settings, and the reality that the cost of access remains high.

English is not the academic language of many nurses: South Africa has 11 official languages (SouthAfrica.info
2012) with English being the first language of only $8 \%$ of the population. Considering the postgraduate student group specifically, a correlation with this national language demography is evident: whilst all speak English, it is the second or third language for the majority of the student group.

Despite these statistics, English is the official language of commercial and public life, tertiary education and healthcare settings (SouthAfrica.info 2012), but exclusive use is rare. In health care, whilst documents and formal communication are in English, other languages, primarily Isixhosa and Afrikaans in the Western Cape, where the university is situated, are often spoken in formal and informal communication in clinical settings. This has an impact on a students' fluency in the technical clinical language, and presents a considerable challenge when completing a clinically focused postgraduate programme at an English-medium university.

Blum-Kulka (1982) reported that second-language learners often find it difficult to communicate their intended message in a way that is both socially appropriate and technically correct, and Festman (2012) describes how cross-language interference can also occur. Certainly in the multilingual South African context neither of these situations is uncommon.

The need to assist students in the development of fluency in a specialist technical language has been described by other authors, who recommend repeated exposure to the language as one method that can be used to achieve fluency (Pawlak, Waniek-Klimczak \& Majer 2011; Ernst-Slavit \& Mason 2011). Encouraging students to vocalise the language within the education environment is proposed as another method to provide students with the confidence to then speak it in other environments (Pawlak 2011). In the study setting it had become clear that fluency in the specialist, technical languages of research and clinical nursing proved challenging for many students.

Published work is often from foreign, mostly wealthy settings. The geographical origins of published articles present a second challenge to research application. Ciliska et al. (2001) report hesitancy in nurses to read if they cannot appreciate how the literature could be applicable to their practice. For nurses in South Africa this may be particularly relevant given that the majority of existing nursing research articles still originate from European, North American and Australasian settings. Healthcare in well-resourced settings can be distinctly different from that in South Africa, and conclusions and recommendations to local clinical nursing practice are not always easy to apply.

The cost of printed journals remains prohibitively expensive for many nurses worldwide. This is particularly true within an African context, since salaries are proportionally low and unfavourable exchange rates significantly increase the cost of professional journals from overseas. Whilst the majority 
of journals are accessible electronically, these too come with high subscription rates.

University libraries do subscribe, and likewise provide sufficient computer facilities and information technology. However, this only ensures access to formally registered students. When students are off campus, online reading may be restricted by inefficient Internet access and insufficient bandwidth, which is still comparatively expensive in South Africa. The growing body of resources like Google Scholar and other open access sites widens the availability of journal articles considerably, but knowledge of these sites remains limited. As a result, actual access to nursing literature remains a challenge for registered nurses.

Whilst journal clubs have been established in other settings to overcome barriers to access, a literature search (using the key words 'journal club' and 'Africa' in CINAHL, Medline, ERIC, Health Source and Africa-Wide Information) yielded no reports of journal clubs operating in this region. At the time of implementation of this journal club, the educators were unaware of any clinical or educational journal clubs of nurses active locally.

Considering the additional challenges faced by local registered nurses to access and read available literature, the educators asked the following question: How can a regular journal club within the one-year programme, in which students present and participate, assist students to find, read and consider integrating findings of research literature into practice in their local context?

\section{Research objectives}

The aims of this study were to first introduce a journal club as an educational strategy into the postgraduate children's nursing programmes at UCT and then to refine the journal club structure to ensure alignment with the programme, whilst maintaining it as an enjoyable activity. Nurturing enjoyment could increase the possibility that students would continue to read after graduating and returning to their clinical settings.

The specific objectives were to design and introduce a journal club into the postgraduate programme that would:

- Increase the students' awareness of, ability to access and to read professional nursing research literature.

- Facilitate students' consideration of presented research literature to their varied clinical settings.

- Provide an opportunity to aid their understanding of the research process and increase their ability to judge the strength of the evidence.

Thereafter also to:

- refine the journal club format to ensure that it aligns to teaching and clinical learning needs of the students; and

- track the process by gathering and analysing data and linking findings with proposed design changes for the next academic year cycle with rigour.

\section{Contribution to the field}

Journal clubs have been extensively used and describe in various disciplines, including mostly clinical settings in medicine and nursing. Reports of implementation in settings where researchers aim to increase evidence-based practice in clinical settings are increasingly seen. The uses of various adaptations of journal clubs are more recently evident as educational interventions.

This article describes the design and implementation of a journal club within a postgraduate diploma programme aimed at registered nurses, many of whom have very little or no prior exposure to or training in clinical or other research. In addition, this study describes a cyclical design used to refine a structure to engage and ultimately enrol registered nurses working in resource limited clinical settings. It also adds the perspective of a journal club providing participants with the opportunity to speak and hear their specialised technical languages in the safe context of peer discussions. Lessons learnt from this study are provided in the format of a set of recommendations that could be used to guide the establishment of a journal club in similar postgraduate settings.

\section{Literature review}

Practising nurses report that it is a challenge to keep abreast of and apply findings from research literature. Primary reasons cited for this include a lack of time and access to journals, insufficient training in skills to search for and critique literature, and inadequate understanding of research methodology (Campbell-Fleming, Catania \& Courtney 2009; Pravikoff, Tanner \& Pierce 2005; Kleinpell 2002; Goodfellow 2004). Pravikoff et al. (2005) also note that organisational beliefs may prevent nurses from applying research in practice; nurses may be perceived to be uninterested in research, or the organisation may consider incorporation of research findings to be unachievable.

Goodfellow (2004) states that it is important that students learn to use research in making clinical decisions and proposes the use of a journal club as one strategy to facilitate this learning. A journal club is broadly described as a professional group who regularly meet to read and critique recently published, scholarly research articles, and to discuss their applicability to practice (Hughes 2010; Linzer 1987). First recorded as being used by Sir William Osler in 1875 as a way of distributing unaffordable medical periodicals (Linzer 1987), the use of journal clubs has evolved over time and they are used by a wide range of healthcare professionals in clinical, research and educational settings. The benefits of journal clubs are extensive and are summarised in Box 1.

BOX 1: Benefits of journal clubs.

Promote professional reading.

Update of clinical knowledge.

Clinicians' improved ability to critically evaluate published research.

Facilitated interpretation and application of appropriate research to practice. Improved presentation skills in educational settings.

Source: Society for Vascular Nursing Research Committee 2009; St Pierre 2005; Linzer 1987 


\section{Research method and design Research design}

An action research approach was chosen by the research team of six educators to refine an intervention that, whilst it is well described in other settings, needed to be adapted to meet the particular needs of the study environment. Action research is described as 'a systematic approach to investigation that enables people to find effective solutions to problems they confront in their everyday lives' (Stringer 2007:1). It is essentially a method of finding solutions and guiding refinement of interventions in response to a described practice challenge (clinical and educational), by those people using them, to ensure that they are most appropriate for and effective within the identified setting. Zuber-Skerrit (1990) maintains that it is particularly important for practitioners to reflect on their own practice in rigorous ways in settings where continued current practice could prevent change for improvement.

Successive cycles of assessing and/or reflecting, planning, acting and observing were used throughout the journal club's implementation (Figure 1). Every cycle served to increase the knowledge about the setting, thus enabling further refinement of the intervention. Three cycles spanning five eight-month academic calendars (from 2008 to 2012) are described in this article.

\section{Data collection method}

Data collection methods were guided by outcomes of previous cycle. Two data sets were consistently gathered and collated throughout: lists and a review of the presented articles and continuous educator and/or facilitator reflections. In cycle 1 (3 academic years, 2008-2010) these 2 data sets were analysed to inform the planning stage of the next cycle.

In cycle 2 (one academic year, in 2011) and cycle 3 (one academic year, in 2012) 2 series of rapid appraisals from students were added. Rapid appraisal is described as a technique used to gain insight into the practice and views of people within a specific population of interest (Bowling 2009), and can encompass the use of various data collection methods (Vondal 2010).

In this context a short rapid appraisal tool was completed by the students at the end of the academic year in cycle 2, to gather specific information required at that stage of the journal club development. The tool aimed to answer a question that arose from educator reflections about whether previous journal club experience influenced student expectations and participation. The initial rapid appraisal asked questions about students' previous experiences to ascertain the assumptions educators had made at the beginning of the study. The questions were again asked at the beginning of the last cycle. Responses confirmed that students in both year groups did have very limited previous exposure to reading published literature. The additional information gathered at different times during the last two cycles confirmed assumptions and the value refinement of the journal club format.

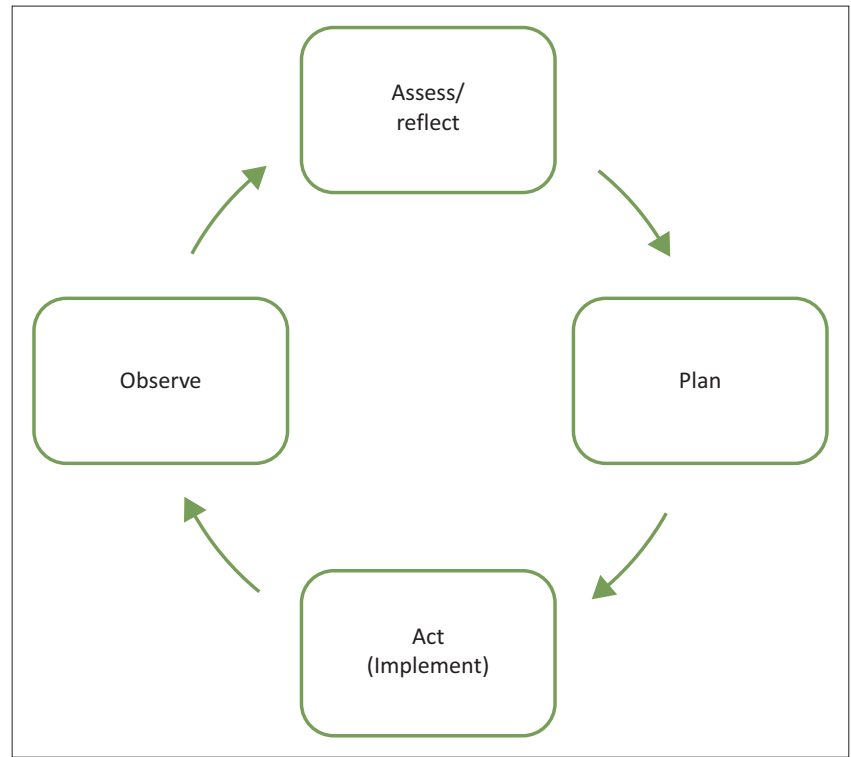

FIGURE 1: The action research cycle.

This was a practice improvement activity in which educators were the primary participants. The initial educator team of two grew to six members, and all became researchers in this study. Students were not included as participants in the design process and therefore are not reported as participants. All students in the period of research participated in journal club groups, and in the final two cycles contributed to two rapid appraisals.

\section{Results}

\section{Action research cycle 1 (Academic years 2008-2010)}

Design and implementation of a journal club in response to assessment of the student research context

Initial evidence on specific challenges faced by registered nurse in the postgraduate programmes led to the design and implementation of a journal club as an educational intervention in 2008. Initial journal club sessions were based on the evolving understandings of newly appointed educators into a recently re-established postgraduate programme. Teaching a group of registered nurses from various geographical settings in South Africa required drawing on their own professional and clinical experience, including that of attending medical journal clubs.

A designated clinical day was established in the weekly timetable and a journal club was added to the schedule. Student attendance on this day was mandatory. To illustrate to students how a journal club works, educator-facilitators chose and presented an article and led the discussion for the first 2 journal club sessions of a 16-week cycle. On each of the remaining 14 days allocated within the academic year, 2 students were each required to choose, summarise and present one research article of interest. Students used Microsoft PowerPoint ${ }^{\circledR}$ to guide their presentation.

As registered students these registered nurses now had access to a well-equipped university library, supported by a team 
of librarians. Tutorials given at the start of the programme provided information about how and where to search for literature.

Following the students' presentation, discussion was facilitated by the educator-facilitator using an adapted version of Nancy Kline's Thinking Environment approach (Kline 1999). In a structured round of conversation, each student had the opportunity to ask one clarifying question about the article that had been presented. This was followed by another round in which each student was asked to reflect on the applicability of the study results to their own practice setting.

\section{Outcomes of analysis of collated data from cycle 1}

At the end of these first three 16-week periods (2008-2010) the research team gathered to analyse data compiled from the educator reflections written after each journal club. A review of all the articles chosen by students and facilitators was collated and considered alongside reflections. Analysis identified both benefits and challenges associated with the initial structure of the journal club.

Journal club benefits: Benefits of the journal club included an immediate increased exposure of students to journal articles. Each student group had heard and participated in discussing 28 articles presented over the 16- week period. Educator reflections indicated students' initial surprise at research relevance to nursing practice, and increasingly evidenced students' broader understanding of the notion that research could be conducted by nurses. Students' realisation that, irrespective of origin, research could often be relevant - at least in part - to local settings, was also evident in educator reflections. The practical aspects of choosing and summarising articles provided an opportunity for students to practice their newly acquired knowledge of literature searching, along with skills related to computer technology. The requirement to verbally present the journal article ensured that each student had the opportunity to speak the technical and specialist clinical information and language to a group of peers.

Journal club challenges: Two clear challenges were associated with the initial journal club structure. Firstly, review of the articles chosen and presented by students during this period revealed that many of the articles were not well suited to their learning. Educator reflections confirmed that some of the articles were too complicated for the students to understand; others were not relevant to the specialties of children's nursing or children's critical care nursing. Some were interesting but very difficult to relate to current or local practice, and others did not describe research studies. Secondly, even though 28 articles were presented, students were only required to read the one that they were responsible for finding, summarising and presenting.

These benefits and challenges meant that the initial journal club format was contributing to the study goal of increasing student awareness of published research literature and was providing them with an opportunity to consider application in local practice settings. The format was, however, not maximising the whole student group's opportunity to practise accessing and reading published papers.

\section{Action research cycle 2 (Academic year 2011)}

\section{Refinements based on outcomes of cycle 1 review}

Outcomes and learnings from cycle 1 informed the redesign of the structure of the journal club. These changes were implemented from the start of the 2011 academic year.

Educator-facilitators would now select the articles to increase suitability, a strategy adopted by Owen, Wheway and Anderson (2001) and also recommended by Mallick (2008) for any journal club in which the group is still learning about research. Criteria by which to choose the articles were agreed upon by all the educators involved (Box 2).

To enable students to read the article before the journal club, whilst also increasing their need to practise locating articles themselves, the educators did not provide a full text copy of the article to students, but posted only sufficient information about the article on the student intranet system to assist them in locating the online resource themselves. Educators anticipated that this would take students more time and therefore reduced the number of articles presented each week from two to one.

\section{Outcomes of analysis of collated data after cycle 2}

At the close of the 2011 academic year data from educator reflections and article titles collated with reviews were again analysed. The initial analysis of educator reflections showed evidence of students being more 'research aware' than in previous groups. Educators now became interested in finding out whether students had any previous experience of reading published literature or participating in journal clubs, as it had been assumed from the start of the study that this was not the case. A rapid appraisal was done at the end of cycle 2 to elicit this information from all students in the student group. Here an additional number of open-ended questions and an invitation for additional comments also allowed educators to obtain feedback from students regarding their enjoyment of journal clubs and the perceived benefit from journal clubs to their learning.

Analysis of educator reflections revealed that choosing specific articles allowed educators to align the weekly reading

BOX 2: Criteria for selecting articles for journal club.

Must describe a research study.
Simple in language and design.
Nursing related.
Appropriate to African region.
Pathway specific: Child or child critical care nursing.
Topic specific: Identified as educational need or topical nursing issue.
Ideally a maximum of 10 pages.
Accessible through an open resource website or the UCT database.
Source: Society for Vascular Nursing Research Committee 2009; St Pierre 2005; Linzer 1987.
UCT, University of Cape Town


and discussion with current issues in children's nursing or critical care nursing of children, or to topics related to identify student needs. Prior selection of articles facilitated educators' planning of the approach or discussion focus ahead of the session. Reflections also revealed excitement at the progression of students' knowledge and understanding, especially related to research concepts over time.

Sourcing of articles by all attending students increased the number which students found and read from one or 2 each to at least 14 across the 16-week period. It also allowed for better preparation, and a greater willingness of all students to participate in the discussions. This provided an opportunity for students to practise the specialised technical language, and to express opinions and demonstrate levels of understanding in a safe, educational environment. Educators experienced a general increased student interest and enthusiasm for the intervention in comparison to previous years.

Questionnaire responses: Analysis of the qualitative questions in the rapid appraisal demonstrated students' recognition of the learning opportunities provided by the journal club, and confirmed many of the educator observations. Encouragingly, students reported that they recognised the capacity of journal club to aid the application of research to their clinical practice. They appreciated the post-presentation discussion, recognising that this allowed them the chance to clarify foreign concepts, learn how to critique and receive the opinions and thoughts of others. In particular, students noted that the discussion was enriched by the fact that they [the students] originated from a variety of different clinical settings.

Students did, however, remark that they did not always have sufficient time to prepare for journal club, citing reasons of late notification of the article title by the educators, the article being too long or the need to dedicate time to other academic activities. They described how this had the potential to result in poor presentations and a reduced capacity to contribute to the discussion.

Students also confirmed educator perceptions that being required to source the article and prepare a summary forced them to utilise literature-searching databases and improve their computer technology skills. For many this was regarded as beneficial. For some students this was a considerable challenge; these students would have liked more guidance from educators to help them complete these tasks.

\section{Action research cycle 3 (Academic year 2012) Reflection on cycle 2 and refinement of the journal club intervention}

In summary, reflections from cycle 2 revealed that the refined structure of the journal club met the specific objectives of the intervention and was increasingly appropriate to the needs of the setting and participating students. Minimal minor changes to the intervention were therefore planned for cycle 3.
In response to the students' qualitative responses in 2011, the educators made the commitment to inform the 2012 students of the article details a week ahead of time and to ensure that selected articles adhered to the criterion of a maximum of 10 pages. Increased tuition in the use of PowerPoint ${ }^{\circledR}$ was also planned for inclusion in the Orientation/Information Technology programme provided to students at the start of the academic year.

As educator reflections had revealed the need to better align the clinical and journal club learning, the structure of the day was adapted in the following academic year. Each clinical Tuesday had a clear clinical focus or theme, for example managing pain or diarrhoeal disease. The journal club, patient presentation and tutorial were then intentionally aligned to the theme (Figure 2).

\section{Outcomes of analysis of collated data after cycle 3}

Analysis of educator reflections at the close of the 2012 academic year was added to analysis of the student rapid appraisal questionnaire. There was an increase in the class size in the 2012 academic year in the children's nursing pathway. This necessitated separating the class into two groups, for which two separate journal clubs were then run in succession; each journal club was facilitated by one educator. Educators' reflections from these highlighted differences in the way in which different groups of students presented the same article and how the quality of the article preparation and presentation impacted on the subsequent discussion. The smaller student group in the critical care pathway meant that two facilitators were available for each group. Reflections revealed the significant benefit of having two facilitators present, as their different areas of clinical and research expertise enhanced the journal club discussion. All educators noted that during this academic year the students seemed much more interested in discussing the research methods being used in the articles.

As in the questionnaire responses from 2011, the students highlighted the fact that the post-presentation discussion facilitated their ability to consider application of the research to their own practice, and that they particularly enjoyed hearing about practice in settings other than their own. The benefit of being required to present research articles was confirmed, with more responses specifically describing the value of having to 'speak out', and that this increased their confidence. Additional tuition in the use of PowerPoint ${ }^{\circledR}$ was requested by some.

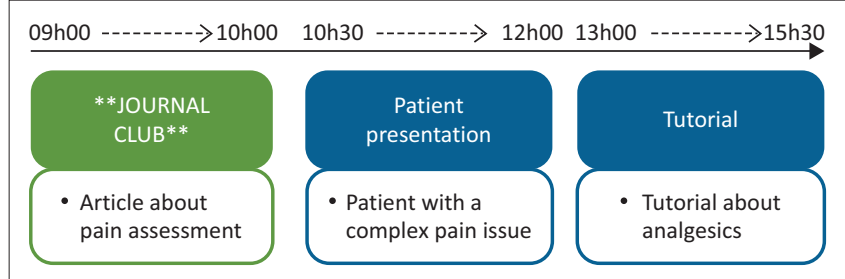

FIGURE 2: An example of the timed schedule and linked content within a typical clinical teaching day. 
As in 2011, students commented that preparation for journal club took a considerable amount of time. However, the 2012 students felt that that this was not due to late notification of the article, but rather that the time required to prepare negatively impacted on their capacity to prepare and ultimately to participate. Students felt that a poor presentation led to a lack of interest in other students and reduced the available time for discussion. Linked to this, a number of students suggested that the time allocated to journal club should be increased or that the intervention should occur more often.

\section{Summary of quantitative results of the student questionnaires}

The need for and benefit of holding a journal club in this setting were confirmed through the collective examination of the quantitative results of the two completed questionnaires. Prior to completing this programme few students had previously attended a journal club and some had not previously read a research article. Indeed, very few were confident in their abilities to search for and source an article, or in their knowledge of research methodology. General access to articles was similarly reported as lacking but, encouragingly, the majority reported that they perceived it to be 'good to read'.

Attendance at journal club for the period of the year brought about considerable change. The majority reported enjoying attending journal club (Figure 3). Increases were reported in awareness of and access to journal articles, literature-searching capabilities and comprehension of research methodology. A belief that journal club had made them consider their practice and increased their confidence to speak up about research they had read about was indicated. The majority regarded the intervention as having the potential to influence clinical practice, and for this reason many stated that they had considered starting a journal club in their home settings on completion of the course.

The students of 2012, in comparison to those of 2011, commenced the year reporting a considerably greater exposure to research articles, and better understanding of

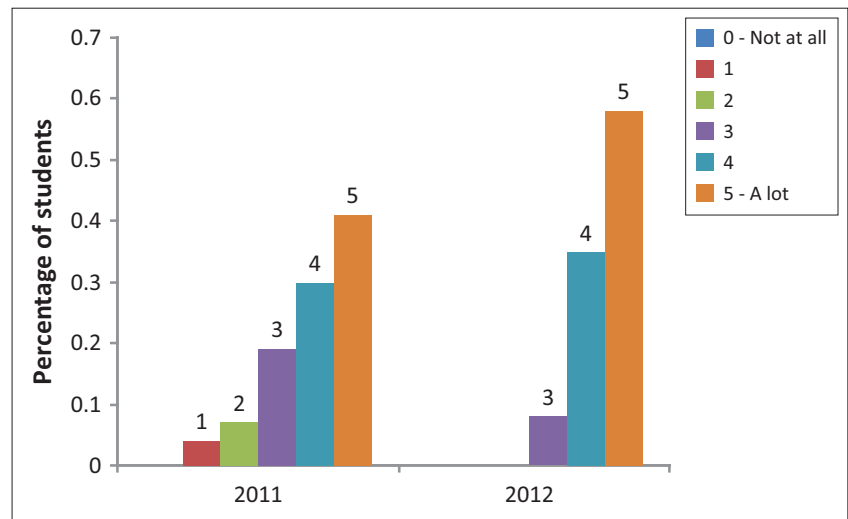

FIGURE 3: Students' responses to the question 'To what extent have you enjoyed journal club?' the literature-searching and research methodology. This was partly due to an increase in the number of degree-prepared students from other African countries, some on master's programmes, having joined the programmes.

\section{Ethical considerations}

At UCT educational interventions such as teaching practices and assessment methods are continually reviewed and improved, and students formally evaluate all courses. Such review and evaluation is not centrally regulated and does not require formal ethics review.

Participation in journal clubs was not marked and did not lead to the awarding of academic credits to unfairly benefit or harm attending students in any way. Participation was regarded as a learning opportunity to prepare students for their role as specialist children's nurses following completion of the course. The implementation of journal clubs was not experimental in design, as they had been designed and proven in other contexts. Rather, the intervention was being refined as an educational intervention in this context and, as such, students did not have pressure to participate or an option to opt out of participating.

\section{Discussion}

Registration as a student at UCT automatically increases the physical access of nurses to published nursing articles. Student status provides these registered nurses with membership to the university library, which subscribes to a number of nursing and healthcare journals. Additional tutorials in the academic programme contribute to library use and skills to conduct electronic literature searches. Access alone, however, does not necessarily increase reading and application, since for many of the students on this programme prior exposure to nursing research is extremely limited, decreasing the understanding of or need for - and therefore benefit of - reading nursing articles.

Introduction of a journal club as an educational intervention in this action research process increased students' exposure to reading nursing literature in this setting. The requirement for students to regularly prepare for and take part in the journal club presented them with a need to practice their newly gained literature-searching skills and to read research articles.

Refining the journal club structure in response to these student groups' needs meant that the educators could encourage different learning as deficits were revealed. The decision to supply some details prior to the journal club required more students to find and read the same article. This not only increased the opportunity to search for and find articles but also increased student participation in the discussions. Switching to educator-chosen articles ensured that the selected articles were most relevant to current student learning, the students' clinical specialty and local nursing practice. 
Discussions that followed the presentation of each article provided an opportunity for students to improve their understanding of research methodologies in applied ways. The intentional application to the current clinical context and timetable topic increased opportunities to consider research applicability in more practical and immediate ways. The degree to which the discussion achieved this was influenced by students' ability to participate, which in turn was determined by their level of preparation. The educators' familiarity with the article topic and research methodology further facilitated the effectiveness of discussions. Both aspects of facilitator and participant preparedness are confirmed by Deenadayalan and colleagues (2008) as being important to a constructive discussion. Refinement of the journal club structure, specifically the shift to having educator-chosen articles, was key in this setting. Discussions could also be facilitated in ways that enabled students from very different clinical settings to contribute different opinions and experiences to discussions.

Some prior understanding of the research process and methodology also contributed to the successful outcome of the journal club. In the 2012 academic year the students described more understanding of research methodology prior to their participation in the journal club. Educator reflections revealed that discussion in those student groups often focused on the research methods being used in the articles. This could be explained in part by better baseline knowledge of research methodologies, as more students on the course had completed research modules in other modules or programmes. Familiarity with the research process could establish a different basis from which these students question and deepen their understanding. The advantage of more questioning was that all those participating in journal club gained from the increased depth of the discussion. The discussions were even more valuable as they were grounded in the real clinical contexts of the students' variety of settings.

Another previously unrecognised value of journal clubs in this setting arose from starting to understand the value of the opportunity to speak and hear the specialised technical language of children's nursing and research methodology being spoken. In these small group discussions students practised the technical language, their pronunciation and the cadence of the language in a safe and supported setting. They listened to one another and on occasion laughed at themselves and how they had thought the words sounded. The authors believe that these safe spaces of talking the clinical and technical language of practice have the potential to have a considerable impact on learning and practice.

After participation in journal club the students described increased confidence in their ability to articulate themselves. Educators surmise that this further assisted the students in forms of assessment in which they were required to converse or orally present clinical information. The impact in the clinical setting on the students return, post completion of
BOX 3: Recommendations for starting a journal club.

Keep group size small (maximum 10 people, plus a facilitator)

Start by having the facilitator choose the journal articles

Make the article, or details of the article, available to the group at least a week before the meeting.

Ensure that an experienced facilitator presents the article in the first journal club meeting.

Ensure that the facilitator has some knowledge of the topics and research methodology.

Ensure that sufficient time is provided for structured discussion and that all participants are encouraged to voice their opinion as a contribution.

Source: Society for Vascular Nursing Research Committee 2009; St Pierre 2005; Linzer 1987

the course, has not been measured and is certainly an area to explore. Overall the students reported that they enjoyed participating in journal club.

\section{Limitations of the study}

This educational intervention was not novel, but implemented and refined to tackle the needs of students in a particular educational and geopolitical setting. This article describes an educator implementation and review process utilising the process of action research. A limitation is that full student evaluation is not included. The study results were not intended to be generalisable, so the lessons and process rather than outcomes of the intervention were the intention. These lessons and the process could still be of interest to readers working in other educational settings.

\section{Recommendations}

The use of a journal club as an educational intervention can successfully increase the exposure of postgraduate nursing students undertaking clinical specialist nurse training programmes to published research articles. Use of journal clubs as an educational intervention in other nursing disciplines in similar settings is therefore a recommendation. The authors would recommend that measures of success are articulated by student participants in the design phase and then consistently evaluated.

Lessons learnt from this process have been articulated into a set of recommendations (Box 3) that could be used to guide the establishment of a journal club in other similar postgraduate settings.

\section{Conclusion}

Nurses practising in the clinical settings in which the Child Nurse Practice Development Initiative is engaged in numerous local, South African and other African locales are increasingly challenged to improve care. This also means ensuring that their nursing practice remains aligned to the most recent and applicable evidence base.

Journal clubs in this educational setting clearly facilitate an increase in student awareness and reading of nursing literature. The design of the structure, which was intentionally responsive to registered nurse student learning needs, offered the opportunity to consider the application of published research to current nursing practice. 
An unanticipated but extremely valuable outcome in this setting was the opportunity for students to become familiar with the specialised and technical language of research, children's nursing and critical care of children and neonates, by speaking in safe peer settings. For nurses, speaking up with understanding may be the first step to contributing evidence-based research thinking in local clinical settings, and journal clubs in both clinical practice settings and clinical postgraduate nursing programmes may be a significant contributor to nurses finding their voice to contribute to best care and clinical decisions.

\section{Acknowledgements Competing interests}

The authors declare that they have no financial or personal relationship(s) that may have inappropriately influenced them in writing this article.

\section{Authors' contributions}

M.C. (University of Cape Town) was the project leader. I.H. (University of Cape Town) Initial concept. A.L., C.D., H.B. and L.A. (University of Cape Town) Concept development. A.L., C.D., H.B., I.H. and L.A. (University of Cape Town) Tracked implementation of journal club, gathered data, and contributed to article outline. C.D. and M.C. analysed data and prepared manuscript.

\section{References}

Blum-Kulka, S., 1982, 'Learning to say what you mean in a second language; a study of the speech act performance of learners of Hebrew as a second language', Applied Linguistics 3(1), 29-59. http://dx.doi.org/10.1093/applin/3.1.29

Bowling, A., 2009, Research methods in health: Investigating health and health services, 3rd edn., Open University Press, Berkshire.

Campbell-Fleming, J., Catania, K. \& Courtney, L., 2009, 'Promoting evidence-based practice through a travelling journal club,' Clinical Nurse Specialist 23(1), 16-20. http://dx.doi.org/10.1097/01.NUR.0000343077.73085.91

Ciliska, D., Pinelle, J., DiCenso, A. \& Cullum, N., 2001, 'Resources to enhance evidence-based nursing practice', Advanced Practice in Acute and Critical Care 12(4), 520-528. http://dx.doi.org/10.1097/00044067-200111000-00008
Deenadayalan, Y., Grimmer-Sommers, K., Prior, M. \& Kumar, S., 2008, 'How to run an effective journal club: A systematic review' Journal of Evaluation of Clinical Practice 14, 898-911. http://dx.doi.org/10.1111/j.1365-2753.2008.01050.x

Denehy, J., 2004, 'Starting a journal club', Journal of School Nursing 20(4), 187-188. http://dx.doi.org/10.1177/10598405040200040101

Ernst-Slavit, G. \& Mason, M.R., 2011, "'Words that hold us up": Teacher talk and academic language in five upper elementary classrooms', Linguistics and Education 22(4), 430-440. http://dx.doi.org/10.1016/j.linged.2011.04.004

Festman, J., 2012, 'Language control abilities of late bilinguals', Bilingualism: Language and Cognition 15(3), 580-593. http://dx.doi.org/10.1017/S1366728911000344

Goodfellow, L., 2004, Can a journal club bridge the gap between research and practice?', Nurse Educator 29(3),107-110. http://dx.doi.org/10.1097/00006223practice?', Nurse Educ
200405000-00008

Hughes, J., 2010, 'Developing a journal club that impacts practice', Gastroenterology Nursing 33(1), 66-68. http://dx.doi.org/10.1097/SGA.0b013e3181ce3b5e

Kleinpell, R., 2002, 'Rediscovering the value of the journal club', American Journal of Critical Care 11(5), 412-414.

Kline, N., 1999, Time to think - listening to ignite the human mind, Cassell Illustrated, London.

Linzer, M., 1987, 'The journal club and medical education: Over one hundred years of unrecorded history', Postgraduate Medical Journal 63, 475-478. http://dx.doi. of unrecorded history', Postgradu
org/10.1136/pgmj.63.740.475

Mallick, M., 2008, 'The seven principles of highly effective journal clubs', American Journal of Infection Control 36(5), E164. http://dx.doi.org/10.1016/j.ajic.2008.04.190

Owen, S., Wheway, J. \& Anderson, M., 2001,'The use of a journal club and clinical seminars on a 4-year undergraduate, pre-registration mental health nursing degree', Nurse Education Today 21, 297-303. http://dx.doi.org/10.1054/nedt.2000.0547

Pawlak, M., Waniek-Klimczak, E. \& Majer, J., 2011, Speaking and instructed foreign language acquisition, Multilingual Matters, Bristol.

Pawlack, M., 2011, 'Instructed acquisition of speaking: Reconciling theory and practice', in M. Pawlak, E. Waniek-Klimczak \& J. Majer (eds.), Speaking and instructed foreign language acquisition, pp. 3-23, Multilingual Matters, Bristol.

Pravikoff, D., Tanner, A. \& Pierce, S., 2005, 'Readiness of us nurses for evidencebased practice', American Journal of Nursing 105(9), 40-51. http://dx.doi. org/10.1097/00000446-200509000-00025

South African Qualifications Authority, 2009, National Qualifications Framework Act, No. 67 of 2008. Government Gazette 524 (31909), 17 February.

South African Qualifications Authority, 2013, 'Publication of the General and Further Education and Training Qualifications Sub-framework and Higher Education Qualifications Sub-Framework of the National Qualifications Framework', Government Gazett e578 (36721), 2 August.

St Pierre, J., 2005, 'Changing nursing practice through a nursing journal club', Medsurg Nursing 14(6), 390.

Stringer, E.T., 2007, Action research, 3rd edn., Sage, Thousand Oaks, CA.

Society for Vascular Nursing Research Committee, 2009, 'Practical tips for starting a journal club', Journal of Vascular Nursing 27(1), 18. http://dx.doi.org/10.1016/j. jvn.2008.12.002

SouthAfrica.info, 2012, The languages of South Africa, viewed 19 September 2013 from http://www.southafrica.info/about/people/language.htm

Vondal, P., 2010, Using rapid appraisal options performance monitoring \& evaluation TIPS, viewed 17 July 2013, from http://transition.usaid.gov/policy/evalweb/ documents/TIPS-UsingRapidÁppraisalMethods.pdf

Zuber-Skerrit, O., 1990, Action research for change and development, Avebury, Brookfield. 